\title{
Desempenho das distribuidoras de energia elétrica e a relação consumo x PIB nos anos de 2006 a 2009
}

\author{
Anderson Catapan* \\ Edilson Antonio Catapan** \\ Dariane Cristina Catapan ${ }^{* * *}$ \\ Diego Felipe Lobo Teles ${ }^{* * * *}$ \\ Amauri Domakoski**** \\ Jocelino Donizetti Teodoro ${ }^{* * * * * *}$
}

RESUMO - Este artigo pretende demonstrar e analisar o desempenho de quatro empresas brasileiras distribuidoras de energia elétrica, dos anos de 2006 a 2009, e apresentar a relação existente entre variação de consumo de energia e o Produto Interno Bruto. Para mensurar o desempenho serão usados indicadores de rentabilidade e será, adicionalmente, usada a análise DuPont. Na parte da relação de consumo e PIB, serão comparados o consumo de energia elétrica e o reflexo disto no PIB brasileiro, abrangendo, também, os anos de 2006 a 2009. Foi possível observar que, nos quatro anos analisados, houve um impacto da crise de 2008 , quando se discorre acerca de desempenho. Neste período foi possível concluir que o consumo de energia elétrica atrela-se ao PIB, mesmo nos anos afetados pela crise.

Palavras-chave: Desempenho. Empresas de energia elétrica. Consumo de energia. PIB.

\section{INTRODUÇÃO}

Entre 2004 e 2008, a economia nacional apresentou um bom desempenho, com o seu Produto Interno Bruto - PIB apresentando crescimento maior que 3\% ao ano. Este desempenho foi reflexo de vários fatores, entre eles destacam-se a obtenção do grau de investimento ao

\footnotetext{
${ }^{*}$ Mestrando em contabilidade e finanças pela Universidade Federal do Paraná. É professor da Pontifícia Universidade Católica do Paraná e sócio-proprietário da Catapan Contadores Associados. Endereço eletrônico: catapancontadores@gmail.com.

** Doutor em engenharia de produção pela Universidade Federal de Santa Catarina. É superintendente de controladoria e participações da Companhia Paranaense de Energia. Endereço eletrônico: catapan@copel.com.

*** Mestranda em ciências veterinárias pela Universidade Federal do Paraná. Médica veterinária da Secretaria do Meio Ambiente de São José dos Pinhais. Endereço eletrônico: darianecatapan@yahoo.com.br.

**** Mestrando em desenvolvimento econômico pela Universidade Federal do Paraná. Economista da Companhia Paranaense de Energia. Endereço eletrônico: diego.teles@copel.com.

***** Mestre em gestão urbana pela Pontifícia Universidade Católica do Paraná. Professor da Pontifícia Universidade Católica do Paraná e diretor de compras da Prefeitura de Almirante Tamandaré. Endereço eletrônico: a.domakoski@gmail.com.

****** Mestrando em contabilidade e finanças pela Universidade Federal do Paraná. Endereço eletrônico: jocelinoteodoro@yahoo.com.br.
} 
Brasil pelas agências avaliadoras Fitch e Standard \& Poor's; a queda do desemprego - de 10,9\% em dezembro de 2003 para 6,8\% no final de 2008; e a aceleração da atividade industrial, que registrou crescimento acumulado de 23,88\% entre o final de 2003 e o de 2008.

Mas grande parte deste resultado deveu-se também ao bom desempenho da economia mundial neste período. E esta começou a sofrer sinais de enfraquecimento ainda em 2007, quando os subprimes americanos começaram a pesar nos passivos dos bancos estrangeiros. $\mathrm{O}$ ano de 2008 foi crítico para a economia mundial e apesar dos esforços conjunturais do governo brasileiro, ainda no quarto trimestre daquele ano a crise chegou ao país. Se em 2008 o PIB brasileiro cresceu 5,14\%, em 2009 houve uma contração de 0,19\%.

Dentro deste panorama macroeconômico, torna-se importante desvendar o comportamento das empresas de energia elétrica. Principalmente sob a ótica das distribuidoras, pois estas são as que diretamente sentem os efeitos de qualquer crise que venha a afetar o mercado interno.

Segundo Catapan (2005), a utilização de índices econômicos constitui-se na técnica mais comumente empregada no meio acadêmico e empresarial, uma vez que já foi amplamente divulgada na literatura inerente ao assunto.

O presente artigo pretende apresentar um panorama geral do desempenho financeiro das quatro maiores distribuidoras de energia elétrica do país - Eletropaulo, Cemig-D, CopelDIS e CPFL Paulista - utilizando-se para tanto de indicadores de rentabilidade coletados para o período 2006-2009, e tendo como pano de fundo o comportamento das classes residencial, comercial e industrial, tradicionalmente as que têm mais peso no consumo destas distribuidoras. Após a apresentação de desempenho, apresentar-se-á uma comparação entre variação do consumo de energia elétrica com a oscilação do PIB.

Para tanto, o artigo está dividido em quatro partes, além desta introdução. A parte dois trata do referencial teórico, com explicações sobre os indicadores utilizados na abordagem. A terceira parte especifica a metodologia utilizada para a construção do artigo. A parte quatro detalha o desempenho das empresas citadas, verificando também o contexto operacional das mesmas, e apresenta a comparação das variações de consumo energético com o PIB. A quinta parte é a conclusão com as considerações finais.

\section{REFERENCIAL TEÓRICO}

Preliminarmente à continuação do estudo é necessário apresentar uma descrição sucinta dos indicadores utilizados na abordagem e que basearão a análise. 
- Rentabilidade do Ativo (\%) = Lucro Líquido (LL)/Ativo Total médio (ATm) - demonstra quanto a empresa obtém de lucro para cada $\mathrm{R} \$ 100,00$ de investimento total (MATARAZZO, 1998), mostrando quanto os ativos da empresa geraram de lucro no período.

- Rentabilidade do Patrimônio Líquido (\%) = Lucro Líquido (LL)/Patrimônio Líquido médio (PLm) - demonstra quanto a empresa obteve de lucro para cada R \$ 100,00 de capital próprio investido (MATARAZZO, 1998). É preciso calcular o indicador sobre o PL médio para não distorcer o resultado, pois se durante o período houve grande variação do PL, seja por aumento de capital, por incorporação de reservas ou pelo próprio lucro gerado, não se pode afirmar que o lucro tenha sido produzido por esse investimento.

Paralelamente a esses dois tradicionais indicadores, o artigo faz uso da análise DuPont, amplamente utilizada pelos administradores financeiros na atualidade. Este sistema funde a demonstração do resultado e o balanço patrimonial em dois indicadores principais da lucratividade da empresa: a Taxa de Retorno sobre o Ativo Total (ROA) e a Taxa de Retorno sobre o Patrimônio Líquido (ROE).

Os indicadores que formam o sistema da análise DuPont são apresentados a seguir:

- Margem Líquida (\%) = Lucro Líquido (LL)/Receita Operacional Líquida (ROL) - demonstra quanto a empresa obtém de lucro para cada $\mathrm{R} \$ 100,00$ vendidos (MATARAZZO, 1998).

- Giro do Ativo (número de vezes) = Receita Operacional Líquida (ROL)/Ativo Total médio (ATm) - Demonstra quanto a empresa vendeu para cada $\mathrm{R} \$ 1,00$ de investimento total (MATARAZZO, 1998).

- Taxa de Retorno sobre o Ativo Total (ROA - \%) = Margem Líquida x Giro do Ativo - permite decompor o retorno da empresa em dois componentes: o retorno sobre as vendas, representado pela Margem Líquida, e a eficiência no uso do ativo, representado pelo Giro do Ativo (MATARAZZO, 1998).

- Multiplicador de Alavancagem Financeira (número de vezes) = Ativo Total (AT)/ Patrimônio Líquido (PL) - indicador de Estrutura de Capital que demonstra a importância do Passivo para a formação do Ativo Total. 
- Taxa de Retorno sobre o Patrimônio Líquido (ROE - \%) = ROA x Multiplicador de Alavancagem Financeira - permite decompor o retorno do capital dos proprietários em três componentes: o retorno sobre as vendas, representado pela Margem Líquida, a eficiência no uso do ativo, representado pelo Giro do Ativo, e o impacto da alavancagem, representado pelo Multiplicador de Alavancagem Financeira.

\subsection{DEFINIÇÕES ACERCA DO PIB}

O Produto Interno Bruto - PIB é definido da seguinte forma pelo Instituto Brasileiro de Geografia e Estatística - IBGE (2010): “Bens e serviços produzidos no país descontadas as despesas com os insumos utilizados no processo de produção durante o ano. É a medida do total do valor adicionado bruto gerado por todas as atividades econômicas.".

O IBGE divulga um estudo intitulado Contas Nacionais Trimestrais. Neste estudo, são apresentados os resultados do PIB brasileiro sob a ótica da oferta e da demanda, que são equivalentes à ótica do produto e da despesa, respectivamente. A ótica da oferta é o somatório dos valores adicionados da Agricultura, da Indústria e dos Serviços. Já a ótica da demanda é o somatório da Despesa de Consumo das Famílias, da Despesa de Consumo do Governo, da Formação Bruta de Capital Fixo, e das Exportações Líquidas.

\section{METODOLOGIA DA PESQUISA}

Para o cálculo dos indicadores de rentabilidade e da análise DuPont, os dados foram coletados dos sites das empresas selecionadas. No cálculo dos indicadores foram feitas reclassificações no Patrimônio Líquido das empresas, de forma que as empresas possam tornar-se comparáveis. Originalmente, cada uma delas tem uma forma de distribuir o lucro gerado. Mesmo uma empresa tomada isolada apresenta diferentes formas de distribuição, como é o caso da Eletropaulo. Em 2006, a companhia distribuiu 34\% dos lucros na forma de dividendos e juros sobre o capital próprio. Já em 2009, este número foi de 101\% do lucro.

Desta forma, em cada empresa apresentamos uma Demonstração das Mutações do Patrimônio Líquido (DMPL) modificada, supondo que dividendos e juros sobre capital próprio não tenham sido distribuídos. No caso da CPFL-Paulista, foram consideradas as reduções do Capital Social em 2006 e 2007, enquanto na Copel-DIS, levou-se em conta o aumento do Capital Social em 2007. 


\section{DESEMPENHO DAS EMPRESAS}

\subsection{ELETROPAULO - ELETROPAULO METROPOLITANA ELETRICIDADE DE SÃO} PAULO S.A.

TABELA 1 - DMPL ELETROPAULO

\begin{tabular}{l|r|r|r|r}
\hline \multicolumn{1}{c|}{ DMPL - Eletropaulo } & \multicolumn{1}{c|}{$\mathbf{2 0 0 6}$} & $\mathbf{2 0 0 7}$ & $\mathbf{2 0 0 8}$ & \multicolumn{1}{c}{$\mathbf{2 0 0 9}$} \\
\hline Lucro/prejuízo do período & 373.371 & 712.631 & 1.027 .109 & 1.063 .194 \\
Dividendos/juros sobre o capital próprio & 126.635 & 715.033 & 1.042 .115 & 1.079 .836 \\
Aumento/redução do capital social & - & - & - & - \\
Saldo inicial do exercício & 1.950 .398 & 2.323 .769 & 3.036 .400 & 4.063 .509 \\
Saldo final do exercício & 2.323 .769 & 3.036 .400 & 4.063 .509 & 5.126 .703 \\
\hline
\end{tabular}

FONTE: Demonstrações financeiras anuais completas (2009) e press-release (2009).

A Eletropaulo é uma companhia de capital aberto, atuando na distribuição e comercialização de energia elétrica em 24 municípios da região metropolitana da grande São Paulo. Em 2009, faturou 34.436 GWh contra 33.860 GWh em 2008, atendendo a aproximadamente 6 milhões de clientes.

Este crescimento refletiu o bom desempenho das classes residencial (4,07\%) e comercial $(4,37 \%)$ e menor consumo da classe industrial $(-8,04 \%)$. O aumento no consumo da classe residencial é explicado pelo incremento do número de consumidores faturados $(3,23 \%)$ e pela elevação da renda real e o aumento da capacidade de consumo da população.

O comportamento da classe comercial pode ser explicado pelos estímulos fiscais como a redução do Imposto sobre Produtos Industrializados (IPI) que manteve a atividade comercial aquecida. Já a diminuição do consumo da classe industrial deveu-se à retração da atividade econômica por conta da crise financeira global, da ordem de 8,4\% no estado de São Paulo.

TABELA 2 - INDICADORES ELETROPAULO

\begin{tabular}{|c|c|c|c|c|}
\hline Indicadores de rentabilidade & 2006 & 2007 & 2008 & 2009 \\
\hline Rentabilidade do Ativo - \% & 3,17 & 5,79 & 8,31 & 8,71 \\
\hline Rentabilidade do Patrimônio Líquido - \% & 17,47 & 26,59 & 28,93 & 23,14 \\
\hline Análise DuPont & 2006 & 2007 & 2008 & 2009 \\
\hline Margem Líquida - \% & 5,45 & 9,91 & 13,64 & 13,21 \\
\hline Giro do Ativo - $\mathrm{n}^{\circ}$ de vezes & 0,58 & 0,58 & 0,61 & 0,66 \\
\hline Taxa de Retorno sobre o Ativo Total (ROA) - \% & 3,17 & 5,79 & 8,31 & 8,71 \\
\hline Multiplicador de Alavancagem Financeira - $n^{\circ}$ de vezes & 5,83 & 4,53 & 3,54 & 2,58 \\
\hline Taxa de Retorno sobre o Patrimônio Líquido (ROE) - \% & 18,49 & 26,27 & 29,41 & 22,47 \\
\hline
\end{tabular}

FONTE: Demonstrações financeiras anuais completas (2009) e press-release (2009).

Os indicadores de rentabilidade da empresa demonstram que a empresa não foi afetada totalmente pela crise, mesmo com a queda de 8,04\% do consumo na classe industrial. Isto pode ser explicado pelo fato de que esta classe responde por $17,52 \%$ do consumo total em GWh pela companhia. Por outro lado, as classes residencial e comercial juntas faturam $74,82 \%$ 
do consumo total. Com isso, tanto a Rentabilidade do Ativo quanto a Rentabilidade do Patrimônio Líquido apresentaram melhora.

Pelo sistema de análise DuPont, verifica-se que a empresa conseguiu manter os altos resultados apresentados em 2008. Manteve estável sua Margem Líquida, refletindo um aumento de 3,51\% no LL e de 10,56\% na ROL; enquanto o Giro do Ativo apresentou melhora, refletindo uma queda de $1,20 \%$ no ATm. De se destacar o elevado ROE, baseado em uma alta alavancagem do PL, e que por consequência elevou o indicador.

\subsection{CEMIG-D - CEMIG DISTRIBUIÇÃO S. A.}

TABELA 3 - DMPL CEMIG-DIS

\begin{tabular}{l|r|r|r|r}
\hline \multicolumn{1}{c|}{ DMPL - Cemig Distribuição } & 2006 & \multicolumn{1}{c|}{$\mathbf{2 0 0 7}$} & \multicolumn{1}{c}{$\mathbf{2 0 0 8}$} & \multicolumn{1}{c}{$\mathbf{2 0 0 9}$} \\
\hline Lucro/prejuízo do período & 769.567 & 774.300 & 709.358 & 338.226 \\
Dividendos/juros sobre o capital próprio & 731.089 & 680.648 & 666.296 & 169.113 \\
Aumento/redução do capital social & - & - & - & - \\
Saldo inicial do exercício & 2.311 .504 & 3.081 .071 & 3.855 .371 & 4.564 .729 \\
Saldo final do exercício & 3.081 .071 & 3.855 .371 & 4.564 .729 & 4.902 .955 \\
\hline
\end{tabular}

FONTE: Demonstrações financeiras anuais completas (2009).

A Cemig Distribuição S. A. é uma sociedade anônima de capital aberto, subsidiária integral da Companhia Energética de Minas Gerais - CEMIG. A companhia foi constituída em 8 de setembro de 2004 e iniciou suas operações em $1^{\circ}$ de janeiro de 2005 , como resultado do processo de desmembramento das atividades da CEMIG.

A empresa possui uma área de concessão de $567.478 \mathrm{~km}^{2}$, compreendendo aproximadamente 97\% do estado de Minas Gerais, atendendo a 6.832 .361 consumidores em 31 de dezembro de 2009, faturando 22.332 GWh durante o ano, contra 22.258 GWh em 2008.

Este resultado refletiu desempenho positivo das classes residencial (8,52\%) e comercial $(5,73 \%)$ e menor consumo da classe industrial (-13,24\%). O aumento no consumo da classe residencial é explicado pelo crescimento do número de consumidores faturados $(3,74 \%)$ associado à influência positiva de variáveis macroeconômicas relacionadas ao consumo das famílias.

TABELA 4 - INDICADORES CEMIG - D

\begin{tabular}{|c|c|c|c|c|}
\hline Indicadores de rentabilidade & 2006 & 2007 & 2008 & 2009 \\
\hline Rentabilidade do Ativo - \% & 8,23 & 7,96 & 7,23 & 3,51 \\
\hline Rentabilidade do Patrimônio Líquido - \% & 28,54 & 22,33 & 16,85 & 7,14 \\
\hline Análise DuPont & 2006 & 2007 & 2008 & 2009 \\
\hline Margem Líquida - \% & 5,45 & 9,91 & 13,64 & 13,21 \\
\hline Giro do Ativo - $\mathrm{n}^{\circ}$ de vezes & 0,58 & 0,58 & 0,61 & 0,66 \\
\hline Taxa de Retorno sobre o Ativo Total (ROA) - \% & 3,17 & 5,79 & 8,31 & 8,71 \\
\hline Multiplicador de Alavancagem Financeira - $\mathrm{n}^{\circ}$ de vezes & 5,83 & 4,53 & 3,54 & 2,58 \\
\hline Taxa de Retorno sobre o Patrimônio Líquido (ROE) - \% & 18,49 & 26,27 & 29,41 & 22,47 \\
\hline
\end{tabular}

FONTE: Demonstrações financeiras anuais completas (2009). 
O comportamento da classe comercial foi influenciado pelo desempenho positivo de quinze ramos de atividade, dentre os dezoito analisados pela empresa. Já o desempenho da classe industrial foi afetado de forma significativa pela crise financeira global. Ainda assim, o número de consumidores da classe manteve-se praticamente estável, apresentando crescimento de $0,91 \%$.

Os indicadores da Cemig-D refletem basicamente dois componentes. O primeiro é o impacto do resultado da classe industrial em 2009. A queda no consumo faturado por esta classe foi tão considerável, que a mesma passou de uma representatividade de 25,03\% no consumo total em GWh em 2008, para 21,64\% em 2009. O segundo foi o efeito da revisão tarifária, com efeitos retroativos a 2008, que representaram uma redução na receita bruta no valor de $\mathrm{R} \$ 213.803$ mil em 2009.

Com isso, os indicadores da companhia apresentaram-se em 2009 num patamar mais baixo do que a empresa vinha conquistando. Mesmo assim, a empresa conseguiu ser mais eficiente na utilização de seu ativo, girando 0,66 seu AT durante o ano e diminuindo a alavancagem financeira do PL, passando de 4,18 em 2007 para 3,77 em 2009. Também se pode observar pela análise DuPont que de 2006 a 2009 a empresa vem aumentando o Giro do Ativo em troca de uma diminuição na Margem Líquida, e que o Multiplicador de Alavancagem Financeira vem diminuindo, representando uma maior participação de capital próprio no AT da companhia.

\subsection{COPEL-DIS - COPEL DISTRIBUIÇÃO S. A.}

TABELA 5 - DMPL COPEL-DIS

\begin{tabular}{lr|r|r|r}
\hline \multicolumn{1}{c}{ DMPL - Copel Distribuição } & \multicolumn{1}{c|}{$\mathbf{2 0 0 6}$} & \multicolumn{1}{c|}{$\mathbf{2 0 0 7}$} & \multicolumn{1}{c}{$\mathbf{2 0 0 8}$} & \multicolumn{1}{c}{$\mathbf{2 0 0 9}$} \\
\hline Lucro/prejuízo do período & 284.679 & 581.460 & 544.374 & 319.713 \\
Dividendos/juros sobre o capital próprio & 117.823 & 171.595 & 166.000 & 186.331 \\
Aumento/redução do capital social & - & 564.760 & - & - \\
Saldo inicial do exercício & 1.532 .506 & 1.817 .185 & 2.963 .405 & 3.507 .779 \\
Saldo final do exercício & 1.817 .185 & 2.963 .405 & 3.507 .779 & 3.827 .492 \\
\hline
\end{tabular}

FONTE: Relatórios de administração (2006-2009).

A Copel Distribuição S. A. é uma subsidiária integral da Companhia Paranaense de Energia - COPEL, e explora a distribuição e a comercialização regulada de energia elétrica a 1.119 localidades, pertencentes aos 392 dos 399 municípios no estado do Paraná, e também ao município de Porto União, no Estado de Santa Catarina.

A empresa faturou 20.242 GWh em 2009 contra 19.633 GWh em 2008, reflexo novamente do desempenho das classes residencial (5,3\%) e comercial (5,9\%). A classe industrial apresentou decréscimo no consumo de 1,0\%, refletindo a redução da produção industrial paranaense em $2,1 \%$. 
Assim como ocorreu com a Cemig, os indicadores apresentaram-se em um patamar menos elevado do que a companhia vinha obtendo anteriormente. $\mathrm{Na}$ Copel a classe industrial respondeu por 33,12\% do consumo total faturado em GWh, sendo esta a principal justificativa para tal desempenho. Ainda assim, o indicador tradicional de Rentabilidade do Patrimônio Líquido ficou em 10,28\%, enquanto o ROE, obtido pela análise DuPont, ficou em 10,68\%.

TABELA 6 - INDICADORES COPEL-DIS

\begin{tabular}{|c|c|c|c|c|}
\hline Indicadores de rentabilidade & 2006 & 2007 & 2008 & 2009 \\
\hline Rentabilidade do Ativo - \% & 7,00 & 12,68 & 10,23 & 5,60 \\
\hline Rentabilidade do Patrimônio Líquido - \% & 17,00 & 24,33 & 16,82 & 8,72 \\
\hline $\begin{array}{c}\text { Análise DuPont } \\
\end{array}$ & 2006 & 2007 & 2008 & 2009 \\
\hline Margem Líquida - \% & 8,28 & 16,37 & 14,46 & 8,22 \\
\hline Giro do Ativo - $\mathrm{n}^{\circ}$ de vezes & 0,85 & 0,77 & 0,71 & 0,68 \\
\hline Taxa de Retorno sobre o Ativo Total (ROA) - \% & 7,00 & 12,68 & 10,23 & 5,60 \\
\hline Multiplicador de Alavancagem Financeira - $n^{\circ}$ de vezes & 2,40 & 2,16 & 1,69 & 1,62 \\
\hline Taxa de Retorno sobre o Patrimônio Líquido (ROE) - \% & 16,77 & 27,36 & 17,34 & 9,06 \\
\hline
\end{tabular}

FONTE: Relatórios de administração (2006-2009).

\subsection{CPFL-PAULISTA - COMPANHIA PAULISTA DE FORÇA E LUZ}

TABELA 7 - DMPL CPFL-PAULISTA

\begin{tabular}{l|r|r|r|r}
\hline \multicolumn{1}{c|}{ DMPL - CPFL-Paulista } & \multicolumn{1}{c|}{$\mathbf{2 0 0 6}$} & \multicolumn{1}{c|}{$\mathbf{2 0 0 7}$} & \multicolumn{1}{c}{$\mathbf{2 0 0 8}$} & \multicolumn{1}{c}{$\mathbf{2 0 0 9}$} \\
\hline Lucro/prejuízo do período & 767.347 & 817.967 & 590.316 & 457.853 \\
Dividendos/juros sobre o capital próprio & 767.347 & 827.776 & 591.957 & 457.853 \\
Aumento/redução do capital social & $(413.288)$ & $(949.769)$ & - & - \\
Saldo inicial do exercício & 1.869 .332 & 2.223 .391 & 2.091 .589 & 2.681 .905 \\
Saldo final do exercício & 2.223 .391 & 2.091 .589 & 2.681 .905 & 3.139 .758 \\
\hline
\end{tabular}

FONTE: Demonstrações financeiras anuais completas (2006-2009).

A Companhia Paulista de Força e Luz é uma sociedade por ações de capital aberto, que presta serviços públicos de distribuição elétrica. A empresa detém a concessão por prazo determinado de 30 anos, até 20 de novembro de 2007, podendo ser prorrogado por no máximo igual período. Sua área de concessão abrange 234 municípios do interior do estado de São Paulo, atendendo a aproximadamente 3,6 milhões de consumidores.

TABELA 8 - INDICADORES CPFL-PAULISTA

\begin{tabular}{|c|c|c|c|c|}
\hline Indicadores de rentabilidade & 2006 & 2007 & 2008 & 2009 \\
\hline Rentabilidade do Ativo - \% & 12,55 & 15,88 & 12,63 & 10,15 \\
\hline Rentabilidade do Patrimônio Líquido - \% & 37,50 & 37,91 & 24,73 & 15,73 \\
\hline Análise Dupont & 2006 & 2007 & 2008 & 2009 \\
\hline Margem Líquida - \% & 19,08 & 18,38 & 13,62 & 9,58 \\
\hline Giro do Ativo - $\mathrm{n}^{\circ}$ de vezes & 0,66 & 0,86 & 0,93 & 1,06 \\
\hline Taxa de Retorno Sobre o Ativo Total (ROA) - \% & 12,55 & 15,88 & 12,63 & 10,15 \\
\hline Multiplicador de Alavancagem Financeira - $\mathrm{n}^{\circ}$ de vezes & 2,72 & 2,20 & 1,93 & 1,51 \\
\hline Taxa de Retorno sobre o Patrimônio Líquido (ROE) - \% & 34,14 & 34,87 & 24,40 & 15,37 \\
\hline
\end{tabular}

FONTE: Demonstrações financeiras anuais completas (2006-2009).

Em 2009, as vendas de energia para o mercado cativo registraram crescimento de 
2,13\%, alcançando 19.977 GWh contra 19.508 GWh em 2008. O destaque foi o desempenho das classes residencial e comercial, que apresentaram crescimento de 5,57\% e de 5,28\% no consumo, respectivamente. Já a classe industrial apresentou decréscimo de 5,38\%, respondendo ao final do ano por $27,45 \%$ do consumo total da companhia.

Para analisar os indicadores da CPFL-Paulista, principalmente os da análise DuPont, é necessário verificar um a um os resultados. O ROE da empresa sofre forte influência do comportamento no decorrer dos anos do seu PL. Em 2006 a empresa reduziu o capital, transferindo investimentos na RGE para a controladora CPFL Energia. Desde 2007, com o PL reduzido e constante na casa dos $\mathrm{R} \$ 490$ milhões, a participação de capitais de terceiros na empresa aumentou. Como consequência, o Multiplicador de Alavancagem Financeira passou de 3,35 em 2006 para 8,86 em 2009, impactando diretamente no ROE da empresa.

Já o Giro do Ativo apresenta a melhor performance entre as cinco empresas analisadas. Isto porque o AT passou de $\mathrm{R} \$ 5.565$ milhões em 2006 para $\mathrm{R} \$ 4.408$ milhões em 2009, enquanto a ROL foi de R 2.227 milhões em 2006 e de R 2.568 milhões em 2009. Ou seja, a empresa conseguiu ser mais eficiente na utilização de seus ativos, passando de um Giro do Ativo de 0,66 em 2006 para 1,06 em 2009. Dentro da análise DuPont, o indicador de Margem Líquida apresentou decréscimo, passando de 13,62\% em 2008 para 9,58\% em 2009.

\subsection{COMPARAÇÃO DE CONSUMO ENERGÉTICO COM O PIB}

As Tabelas 9 e 10 mostram a evolução do PIB brasileiro e paranaense durante os anos de 2006-2009:

TABELA 9 - EVOLUÇÃO DO PIB BRASILEIRO

\begin{tabular}{lrrr|r|r}
\multicolumn{1}{c}{ VARIÁVEIS } & \multicolumn{1}{c|}{$\mathbf{2 0 0 6}$} & \multicolumn{1}{c|}{$\mathbf{2 0 0 7}$} & \multicolumn{1}{c|}{$\mathbf{2 0 0 8}$} & \multicolumn{1}{c}{$\mathbf{2 0 0 9}$} \\
\hline PIB (R\$ milhão) & 929.621 & 986.249 & 1.037 .164 & 1.030 .478 \\
Valor US\$ (fim do período) & 2,1380 & 1,7713 & 2,3370 & 1,7412 \\
PIB (US\$ milhão) & 434.809 & 556.794 & 443.801 & 591.821 \\
Evolução - \% & $3,96 \%$ & $6,09 \%$ & $5,16 \%$ & $-0,64 \%$ \\
\hline
\end{tabular}

FONTE: Instituto Brasileiro de Geografia e Estatística - IBGE (2011).

TABELA 10 - EVOLUÇÃO DO PIB PARANAENSE

\begin{tabular}{l|r|r|r|r}
\hline \multicolumn{1}{c|}{ VARIÁVEIS } & $\mathbf{2 0 0 6}$ & $\mathbf{2 0 0 7}$ & $\mathbf{2 0 0 8}$ & \multicolumn{1}{c}{$\mathbf{2 0 0 9}$} \\
\hline PIB (R\$ milhão) & 55.690 & 59.444 & 61.988 & 61.244 \\
Valor US\$ (fim do período) & 2,1380 & 1,7713 & 2,3370 & 1,7412 \\
PIB (US\$ milhão) & 26.048 & 33.559 & 26.525 & 35.173 \\
Evolução - \% & $2,01 \%$ & $6,74 \%$ & $4,28 \%$ & $-1,20 \%$ \\
\hline
\end{tabular}

FONTE: Instituto Paranaense de Desenvolvimento Econômico e Social (2011).

A Agência Nacional de Energia Elétrica - ANEEL, estabeleceu algumas premissas para os cálculos das revisões tarifárias periódicas das concessionárias de distribuição, publicadas 
na Resolução Normativa n ${ }^{\circ}$, de 5 de abril de 2004:

O consumo agregado de eletricidade tem uma relação de alta dependência com a atividade econômica, enquanto que a elasticidade-preço relativamente baixa da demanda por eletricidade põe em evidência sua baixa resposta a variações no preço do bem. Por isso, a evolução dos preços não é considerada uma variável explicativa de importância. Por outro lado, a demanda por eletricidade está significativamente condicionada pela evolução da quantidade de clientes, por um lado, e pela evolução do PIB nacional. (ANEEL, 2004).

A mensagem que o regulador tentou passar é simples. A demanda pelo bem eletricidade é inelástica a preço, mas elástica a renda. Alterações no consumo de energia não seriam explicadas por alterações no preço, e sim por alterações na renda dos agentes que demandam este bem. Se o preço sobe (desce), o consumidor não alteraria seu padrão de consumo. No entanto, se o PIB cresce (contrai), o mesmo não seria verdadeiro, e o consumidor sofreria incentivos a alterar o seu padrão de consumo. A Tabela 11 mostra o consumo de energia no Brasil, também durante o período de 2006-2009.

TABELA 11 - CONSUMO DE ENERGIA ELÉTRICA NO BRASIL

\begin{tabular}{c|r|r|r|r}
\hline Variáveis & \multicolumn{1}{c|}{$\mathbf{2 0 0 6}$} & \multicolumn{1}{c|}{$\mathbf{2 0 0 7}$} & \multicolumn{1}{c|}{$\mathbf{2 0 0 8}$} & \multicolumn{1}{c}{$\mathbf{2 0 0 9}$} \\
\hline Brasil - GWh & 357.514 & 378.359 & 392.688 & 388.688 \\
Evolução - \% & $3,47 \%$ & $5,83 \%$ & $3,79 \%$ & $-1,02 \%$ \\
\hline
\end{tabular}

FONTE: Empresa de pesquisa energética (2011).

Comparando-a com os números do PIB brasileiro, percebe-se que a premissa tem sustentação empírica. Interessante notar que 2009 foi o único ano de queda no consumo de energia e também de retração do PIB. Podemos afirmar, a partir dos dados, que existe relação, dentro da população selecionada e do tempo delimitado, entre consumo energético e crescimento do PIB.

\section{CONSIDERAÇÕES FINAIS}

O desempenho das quatro empresas analisadas, a primeira vista, podem parecer discrepantes se os indicadores aqui apresentados forem vistos de forma simples. Não se pode tirar uma conclusão isolada a partir de dados isolados. $\mathrm{Na}$ análise deve-se considerar o ambiente operacional e econômico em que a empresa está inserida.

Logo, considerando as assimetrias existentes entre cada uma dessas quatro empresas, seja de mercado, seja operacional, seja econômico da área de concessão, seja de estrutura de consumo por classe, nota-se que todas, de forma geral, sofreram impactos nos seus resultados causados pela crise internacional. Interessante observar que, de regra, as classes residencial e 
comercial sustentaram os números das companhias, enquanto a classe industrial, a mais afetada pela crise, influenciou negativamente os mesmos.

Em relação ao PIB, importante constatação foi encontrada, mostrando que realmente existe relação entre consumo energético no Brasil e aumento do Produto Interno Bruto, respeitando as limitações de população e tempo de pesquisa.

Fica de sugestão para trabalhos futuros aumentar a população de pesquisa, abrangendo todas as empresas de energia elétrica do Brasil, e tornando o trabalho mais relevante dentro do ambiente acadêmico e empresarial.

\section{REFERÊNCIAS}

ANEEL - Agência Nacional de Energia Elétrica. Disponível em: <http://www.aneel.gov.br/>. Acesso em: 1/4/2010.

ASSAF NETO, A. Estrutura e análise de balanços. 7. ed. São Paulo: Atlas, 2002.

CASTRO, N. J. A caminho da consolidação do modelo do setor elétrico. Revista Energia \& Mercados, ano 4, n. 49, p. 34, 2005.

CASTRO, N. J. Problemas e perspectivas da crise financeira do setor elétrico brasileiro. Rio de Janeiro, IFE - Instituto de Economia - UFRJ, n. 1.097, abr. 2003.

CATAPAN, E. A. A privatização do setor elétrico brasileiro: os reflexos na rentabilidade e solvência das empresas distribuidoras de energia. Tese (Doutorado em Engenharia de Produção) - Programa de Pós-Graduação em Engenharia de Produção, Universidade Federal de Santa Catarina, Florianópolis, 2005.

CATAPAN, E. A. Análise comparativa entre empresas congêneres, 2006-2009. COPEL

- Companhia Paranaense de Energia.

CATAPAN, A.; CATAPAN, E.; CATAPAN, D. Cálculo do custo de capital: Uma abordagem Teórica. Economia \& Tecnologia, ano 6, v. 23, out./dez. 2010.

CATAPAN, A.; SCHERER, L.; ESPEJO, M. M. B. O efeito das informações contábeis no mercado de capitais: um estudo bibliométrico no período de 2000 a 2009. Revista Contabilidade \& Controladoria. v. 2, n. 6, p. 47-60, mai./ago. 2010.

CVM - Comissão de Valores Mobiliários. Disponível em: <http://www.cvm.gov.br/.>. Acesso em: 1/4/2010.

EPE - Empresa de Pesquisa Energética. Disponível em: <http://www.epe.gov.br > Acesso em: 1/2011.

HELFERT, E. A. Técnicas de análise financeira. 9. ed. Porto Alegre: Bookman, 2000.

IBGE - Instituto Brasileiro de Geografia e Estatística. Disponível em: < http://www.ibge.gov. br>. Acesso em: 1/2011.

IPARDES - Instituto Paranaense de Desenvolvimento Econômico e Social. Disponível em: $<$ http://www.ipardes.gov.br>. Acesso em: 1/2011.

LOPES DE SÁ, A. Moderna análise de balanço ao alcance de todos. Curitiba: Juruá, 2005. 
MATARAZZO, D. C. Análise financeira de balanços. 5. ed. São Paulo: Atlas, 1998.

MENEZES, E. A. Breve história do pensamento teórico em finanças. Revista FAE Business, n. 4, dez. 2002.

OLINQUEVITCH, J. L.; SANTI FILHO, A. Análise de balanços para controle gerencial. 3. ed. São Paulo: Atlas, 1993.

PADOVEZE, C. L.; BENEDICTO, G. C. Análise das demonstrações financeiras. São Paulo: Thomson, 2004.

SANTANA, E. A. Quando a livre entrada não é socialmente desejável: discussão do atual modelo do setor elétrico brasileiro. Núcleo de Estudos da Economia da Energia - UFSC, 2003.

SILVA, J. P. Análise financeira das empresas. 5. ed. São Paulo: Atlas, 2001. 